\title{
IDENTIFICATION OF A TRYPSIN-LIKE SERINE PROTEINASE DOMAIN ENCODED BY ORF 1a OF THE CORONAVIRUS IBV
}

\author{
D. X. Liu, ${ }^{*}$ I. Brierley, and T. D. K. Brown \\ Division of Virology \\ Department of Pathology \\ University of Cambridge \\ Tennis Court Road \\ Cambridge CB2 1QP, United Kingdom
}

\section{INTRODUCTION}

Avian infectious bronchitis virus (IBV) is the prototype species of the Coronaviridae, a family of enveloped viruses with large positive-stranded RNA genomes. The genomic RNA of IBV is 27.6 kilobases $(\mathrm{kb})$ in length and contains at least 10 distinct open reading frames (ORFs) (Boursnell et al., 1987). Available evidence suggests that five subgenomic mRNA species are produced in virus-infected cells. These mRNAs (mRNAs 2-6) together with the genome-length mRNA (mRNA1) range in length from about $2 \mathrm{~kb}$ to $27.6 \mathrm{~kb}$, and have been shown to share a common 3'-terminus and to form a nested set structure (Stern and Kennedy, 1980ab). Three of these, mRNAs 2, 4 and 6, encode the major virion structural proteins spike (S), membrane (M), and nucleocapsid (N), respectively (Stern and Sefton, 1984). Two of the other mRNAs, mRNA 3 and mRNA 5, have recently been shown to encode three and two viral proteins respectively (Smith et al., 1990; Liu et al., 1991; Liu and Inglis, 1992).

Nucleotide sequence analysis of the genomic RNA of IBV has shown that the 5 '-terminal unique region of mRNA 1 contains two large ORFs (1a and 1b), with ORF 1a having the potential to encode a polypeptide of $441 \mathrm{~K}$ and $\mathrm{lb}$ a polypeptide of $300 \mathrm{~K}$ (Boursnell et al., 1987). The downstream ORF $1 \mathrm{~b}$ is likely produced as a fusion protein of $741 \mathrm{~K}$ with 1a by a ribosomal frameshift (Brierley et al., 1987, 1989). The 1a-1b fusion polyprotein is expected to be cleaved by viral or cellular proteinases to produce functional products associated with viral replication. Several putative functional domains were indeed predicted in either ORF 1a or 1b (Gorbalenya et al., 1989). For example, a picornavirus 3C-like proteinase domain was located in ORF1a between nucleotides 8937 and 9357 and an RNA-dependent-RNA polymerase domain in ORFlb between nucleotides 14100 and

\footnotetext{
${ }^{*}$ Corresponding author.
} 
14798 (Gorbalenya et al., 1989). We have recently reported the identification of a virus-specific $100 \mathrm{kDa}$ polypeptide encoding by ORF $1 \mathrm{~b}$ using a region-specific antiserum V58 (Liu et al., 1994). We show here experiments designed to identify and characterise the proteinase domain responsible for proteolytic processing of this protein from the $1 \mathrm{a}-1 \mathrm{~b}$ polyprotein.

\section{METHODS AND RESULTS}

\section{Expression and Processing of the 100K Polypeptide in a Transient Eukaryotic Expression System}

We have recently reported the identification of a $100 \mathrm{kDa}$ polypeptide in IBV-infected Vero cells using region-specific antiserum V58, which was raised in rabbits from bacterial fusion protein containing IBV sequences from nucleotides 14492 to 15520 . This result suggests that the $100 \mathrm{kDa}$ protein is encoded by the corresponding region of IBV ORF $1 \mathrm{~b}$ and proteolytically cleaved from the la-lb polyprotein (Liu et al., 1994). To test this possibility directly, two plasmids, pIBV10 and pIBV11, which cover IBV sequences from nucleotides 8693 to 13896 and 8693 to 16980 respectively, were expressed in Vero cells using the system described by Fuerst et al (1986). Semi-confluent monolayers of Vero cells were infected with 10 pfu per cell of a recombinant vaccinia virus (vTF7-3) which expresses the T7 phage RNA polymerase, transfected with plasmid DNA from pIBV10 and pIBV11 using lipofectin (Gibco-BRL) according to the manufacturer's instructions, and then labelled with $25 \mu \mathrm{Ci} / \mathrm{ml}\left[{ }^{35} \mathrm{~S}\right]$ methionine. The radiolabelled cells were harvested at 18 hours postinfection, and lysed with RIPA buffer $(50 \mathrm{mM}$ Tris $\mathrm{HCl}, \mathrm{pH} 7.5,150 \mathrm{mM} \mathrm{NaCl}, 1 \%$ sodium deoxycholate, $0.1 \%$ SDS). Immunoprecipitation was carried out using antiserum V58. The results of this experiment are shown in Figure 1. A polypeptide with size approximately 100 $\mathrm{kDa}$ was clearly detectable on immunoprecipitation of pIBV11-transfected cells with serum V58 (Figure 1), indicating that the $100 \mathrm{kDa}$ polypeptide is encoded and processed by IBV sequence information within nucleotides 8693 and 16980.

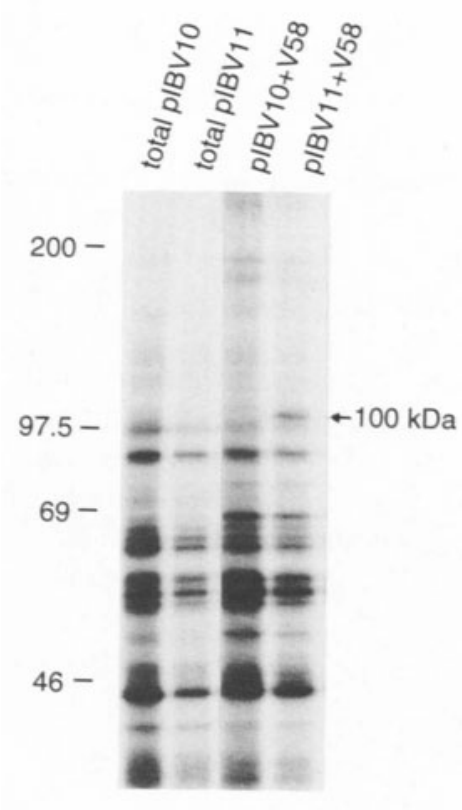

Figure 1. Analysis of transiently expressed ORFs $1 \mathrm{a}$ and $1 \mathrm{~b}$ products from plasmids pIBV 10 and pIBV11, using the vaccinia/T7 recombinant virus expression system. Cells were labelled with $\left[{ }^{35} \mathrm{~S}\right]$ methionine, lysates prepared, and polypeptides analysed directly, or immunoprecipitated with the antiserum V58. Polypeptides were separated on a $12.5 \%$ SDS-polyacrylamide gel, and detected by fluorography. 


\section{Involvement of the Putative 3C-Like Proteinase Domain in Processing of the 100 kDa Polypeptide}

Since the $100 \mathrm{kDa}$ polypeptide is generated when IBV sequences covering the putative 3C-like proteinase domain are present, it is tempting to speculate that this domain and its surrounding regions may be involved in processing of this polypeptide. To investigate this possibility, plasmids pIBV4 and pIBV5, which cover IBV sequences from nucleotides 10752 to 13896 and 10752 to 16980 respectively, and do not contain the $3 \mathrm{C}$ region, were expressed in Vero cells. As shown in Figure 2, transfection of plasmids pIBV4 and pIBV5 directed efficient synthesis of polypeptides with sizes of approximately $118 \mathrm{kDa}$ (pIBV4) and $235 \mathrm{kDa}$ (pIBV5). The $235 \mathrm{kDa}$ polypeptide was immunoprecipitated efficiently by antiserum V58 (Figure 2). Significantly, no $100 \mathrm{kDa}$ polypeptide was detected, confirming the requirement of the $3 \mathrm{C}$-like domain and the surrounding regions in processing of this protein.

\section{Determination of the C-Terminal Boundary of the $100 \mathrm{kDa}$ Polypeptide}

To define roughly the C-terminal boundary of the $100 \mathrm{kDa}$ protein within the polyprotein encoded by IBV sequence within nucleotides 8693 and 16980, two C-terminal deletion constructs (pIBV14 and pIBV15) were made. Plasmids pIBV14 and pIBV15 were constructed by deletion of pIBV11 viral sequences from nucleotide 15537 to 16788 and 15117 to 16980 respectively. As shown in Figure 3, expression of pIBV14 in Vero cells

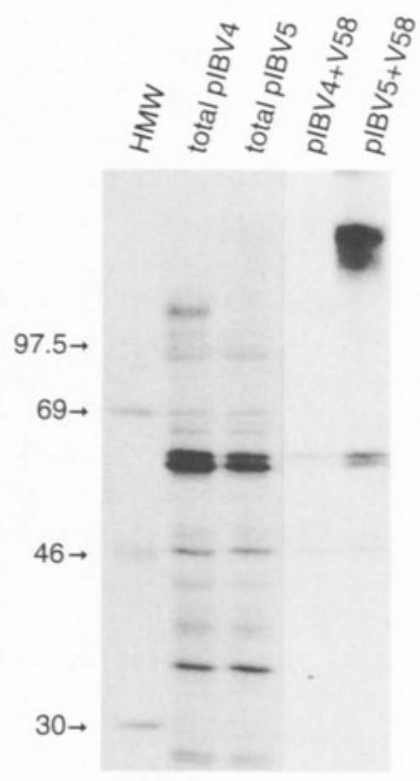

Figure 2. Analysis of transiently expressed ORFs $1 \mathrm{a}$ and $1 \mathrm{~b}$ products from plasmids pIBV4 and pIBV5. Polypeptides were separated on a $12.5 \%$ SDS-polyacrylamide gel, and detected by fluorography. Lane labelled HMW represents high molecular weight markers (Amersham).

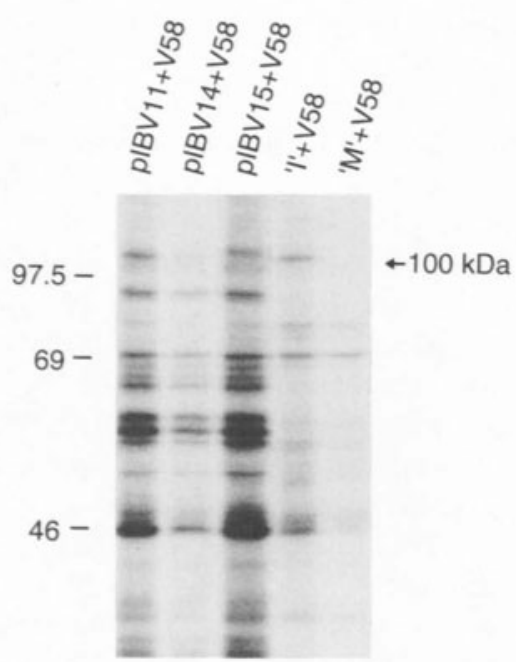

Figure 3. Analysis of transiently expressed ORFs $1 \mathrm{a}$ and $1 \mathrm{~b}$ products from plasmids pIBV 11, pIBV 14 and pIBV15, and detection of polypeptides encoded by ORF $1 b$ in IBV-infected and mock-infected Vero cells. Polypeptides were separated on a $12.5 \%$ SDSpolyacrylamide gel, and detected by fluorography. 'M'-mock-infected Vero cell lysate. 'I'-IBV-infected Vero cell lysate. 
directed the synthesis of a polypeptide co-migrating with the $100 \mathrm{kDa}$ polypeptide identified from IBV-infected and pIBV11-transfected cells. However transfection of pIBV15 yielded a polypeptide that migrated slightly more slowly than the $100 \mathrm{kDa}$ polypeptide did on SDS-PAGE (Figure 3), suggesting that this deletion may block the $\mathrm{C}$-terminal cleavage and therefore lead to addition of some extra amino acids to the $100 \mathrm{kDa}$ polypeptide. Examination of the C-terminal sequence of pIBV15 revealed that 15 additional nucleotides derived from the vector sequence were fused with the ORF $1 b$ frame before a stop codon was reached, resulting in synthesis of a fusion polypeptide with five extra amino acids. This suggested that the C-terminal cleavage site lies close to nucleotide position 15120 .

\section{Effect of Internal Deletion on Processing of the $100 \mathrm{kDa}$ Polypeptide}

To determine further the requirement of the picornavirus 3C-like domain in proteolytic processing of the $100 \mathrm{kDa}$ polypeptide, sequence information covering ORF 1a from nucleotide 9911 to 12227 was deleted from pIBV14, giving plasmid pIBV14Æ1. pIBV14Æ1 was constructed by ligation of a 719 bp DNA fragment (nucleotides 12227-13046), obtained by digestion of pIBV14 with restriction enzyme SnaB1, into PvuII and SnaB1-digested pIBV14, which cut IBV sequences at 9911 and 13046 respectively. Expression of this construction in Vero cells led to synthesis of the $100 \mathrm{kDa}$ polypeptide with much higher efficiency than that from pIBV14. This suggests that the deleted region is not essential for processing of this protein (Figure 4). Furthermore, this deletion reduced the size of the inserted IBV fragment from $6827 \mathrm{bp}$ to $4511 \mathrm{bp}$, which would facilitate subsequent mutagenesis studies of the catalytic domain and the potential proteinase cleavage sites in the la-1b polyprotein.

\section{Mutational Analyses of the Picornavirus 3C-Like Proteinase Domain and a QS Cleavage Site}

Computer-aided analysis has predicted that a picornavirus 3C-like proteinase domain is located in 1a polyprotein between amino acids 2779 and 3085 (Gorbalenya et al., 1989). Three catalytically important residues, $\mathrm{His}_{2820}$, Glu 2843 and $\mathrm{Cys}_{2922}$, presumed to form a catalytic triad, were identified (Figure 5A) (Gorbalenya et al., 1989). Site-directed mutagenesis was therefore carried out to test this prediction. As the preliminary results show in Figure $5 \mathrm{~B}$, mutation of the nucleophilic cysteine residue $\left(\mathrm{Cys}_{2922}\right)$ to alanine ( $\left.\mathrm{pX} 17\right)$ led to synthesis of a polypeptide of approximately $180 \mathrm{kDa}$, representing the full-length product encoded by this construct. Processing of the $100 \mathrm{kDa}$ protein was totally abolished. As expected, alteration of $\mathrm{Glu}_{2843}$ to Asp (pX16.13) did not affect the production of the $100 \mathrm{kDa}$ protein (Figure 5B). Surprisingly, it was consistently observed that neither full-length nor processed products were detected after mutation of $\mathrm{Glu}_{2843}$ to Asn (pX16.3) (Figure 5B).

$\mathrm{C}$-terminal deletion data presented above indicated that a predicted QS cleavage site encoded by nucleotides 15129 to 15135 may be responsible for release the $C$ terminus of the $100 \mathrm{kDa}$ polypeptide. To test this possibility, $\mathrm{Ser}_{892(\mathrm{lb})}$ was mutated to Ala (pX20). As the results shown in Figure $5 \mathrm{~B}$, this mutation did not affect the processing of the $100 \mathrm{kDa}$ polypeptide.

\section{DISCUSSION}

We have recently identified a $100 \mathrm{kDa}$ polypeptide from IBV-infected Vero cells using a region-specific antiserum V58 (Liu et al., 1994). Our previous data suggested that 
a

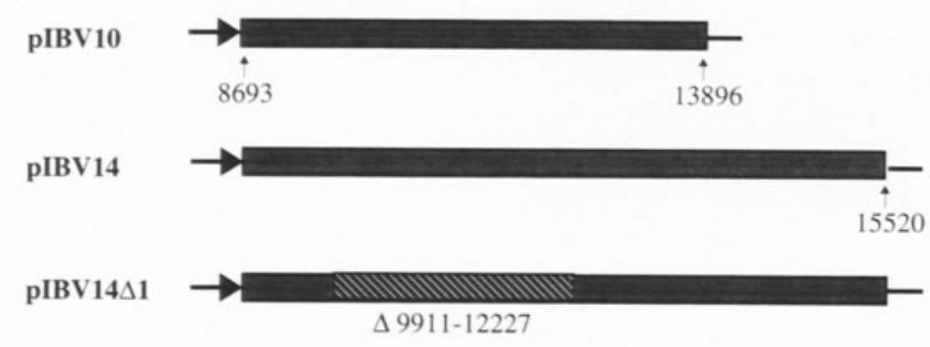

b

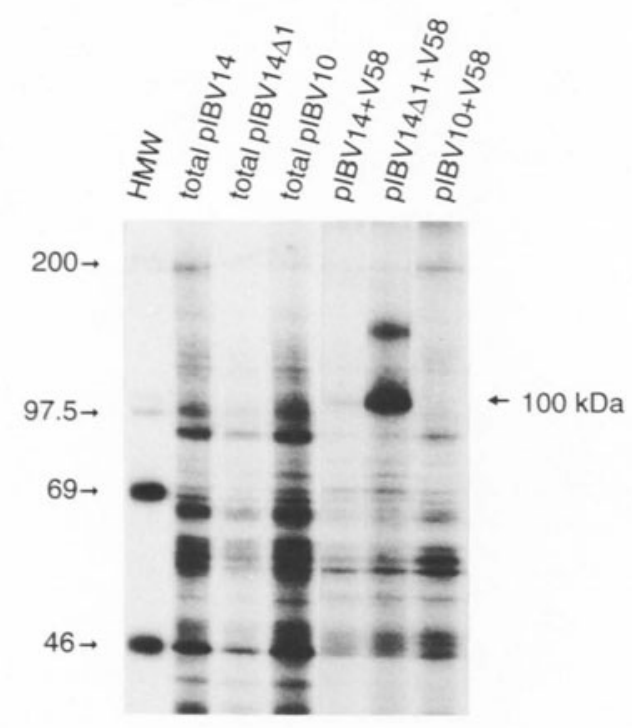

Figure 4. (a) Diagram of the structures of plasmids pIBV10, pIBV14 and pIBV14Æ1 (b) Analysis of transiently expressed ORFs $1 \mathrm{a}$ and $1 \mathrm{~b}$ products from plasmids pIBV10, pIBV 14 and pIBV14Æ1 Polypeptides were separated on a $10 \%$ SDS- polyacrylamide gel, and detected by fluorography

this novel protein is encoded by the 5'-portion of ORF $1 \mathrm{~b}$ up to nucleotide 15520 and may be cleaved from the $1 \mathrm{a}-1 \mathrm{~b}$ fusion polyprotein by the putative picornavirus $3 \mathrm{C}$-like proteinase domain located in ORF1a region from nucleotide 8937 to 9357 . Evidence presented here confirms that the picornavirus $3 \mathrm{C}$-like proteinase domain is involved in processing of the $100 \mathrm{kDa}$ polypeptide. Firstly, internal deletion of ORF 1a sequence from nucleotide 9911 to 12227 rendered no effects on the processing of the protein. Secondly, mutation of the presumed nucleophilic cysteine residue ( $\mathrm{Cys}_{2922}$ ) to alanine abolished the proteolytic processing of the polyprotein encoded by the mutated construct, suggesting that this residue may play an essential role in formation of the catalytıc centre of the proteinase.

Cys-active-centre viral proteinases have been identified in several animal and plant viruses, such as picornaviruses, comovirus and potyviruses (Gorbaleya et al., 1986; Bazan and Fletterick, 1988). Originally, they were classified as cysteine proteinases, but they are considered now belonging to the trypsin superfamily of serine proteinase. Two recent reports on the X-ray crystal structures of the $3 \mathrm{C}$ proteinases from two viruses of the picornavirus family, reveal similar folding of the proteinase polypeptides, RNA-binding sites and means 
A

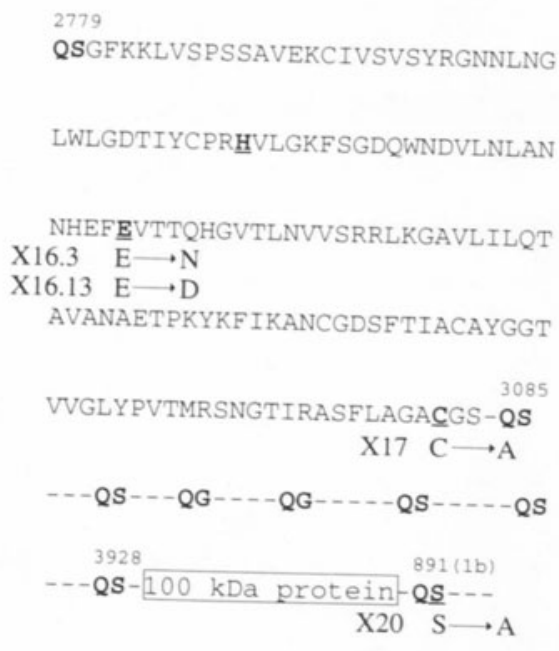

B

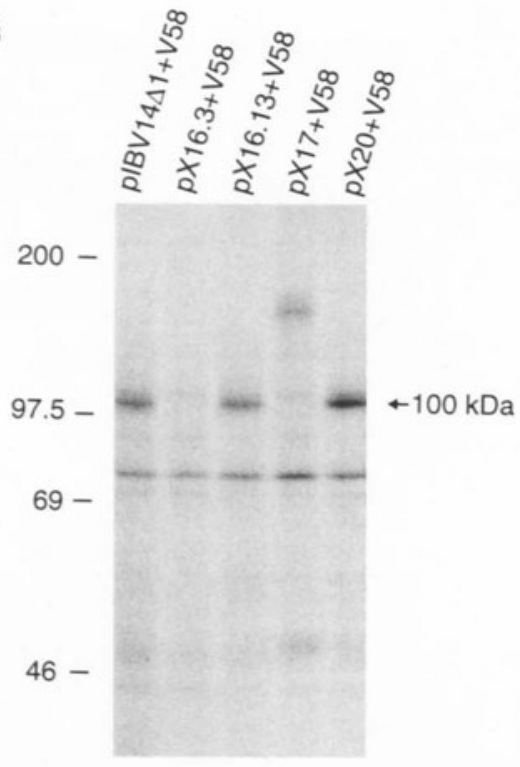

Figure 5. (A) Amıno acid sequence of the presumed picornavirus 3C-like proteinase domain, including four mutants indication of the amino acids changed. The predicated QS(G) cleavage sites and the residues constituting the presumed catalytic triad are shown by bold print. (B) Immunoprecipitation analysis of transiently expressed products from plasmids pIBV14Æ1, pX16.3, pX16 13, pX17 and pX20 using antıserum V58 Polypeptıdes were separated on a $10 \%$ SDS-polyacrylamide gel, and detected by fluorography

for cleaving precursor polyprotein between the viral proteinases and cellular serine proteinases of trypsin or chymotrypsin class (Mattews, et al., 1994; Allaire et al., 1994).

The observation that the $\mathrm{C}$-terminus of the $100 \mathrm{~K}$ polypeptide is specified by ORF1b sequences close to nucleotide 15120 raises the possibility that this polypeptide may be generated by proteolysis at a predicted QS cleavage site encoded by nucleotides 15129 to 15135 (Gorbalenya et al., 1989). Preliminary results reported here showed that mutation of the serine residue to alanine did not alter the proteolytic processing of the $100 \mathrm{kDa}$ polypeptide, suggesting that QA bond might be recognised and cleaved by the IBV serinelike proteinase. For picornavirus $3 \mathrm{C}$ proteinase, it was documented that most cleavages occurred between Gln-Gly peptide bond; less common cleavages were observed between Gln-Ser, Gln-Ala, Glu-Ser, or Glu-Gly pairs (Palmenberg, 1990). More dramatic changes of both $\mathrm{Q}$ and $\mathrm{S}$ residues are underway to delineate the cleavage specificities of the IBV proteinase in the $1 \mathrm{a}-1 \mathrm{~b}$ polyprotein.

\section{ACKNOWLEDGMENTS}

This work was supported by the Agriculture and Food Research Council, U.K.

\section{REFERENCES}

Allaire, M., M. M Chernaia, B. A. Malcolm, and M. N. G. James. 1994. Picornaviral 3C cycteıne proteinases have a fold simılar to chymotrypsin-like serıne proteınases Nature 369:72-76 
Bazan, J F, and R J Fletterıck 1988 Viral cysteine proteases are homologous to the trypsin-like family of serine proteases structural and functional implications Proc Natl Acad Scı USA 85 7872-7876

Boursnell, M E G, T D K Brown, I J Foulds, P F Green, F M Tomley, and M M Binns 1987 Completion of the sequence of the genome of the coronavirus avian infectious bronchitis virus $\mathrm{J}$ gen Virol $6857-77$

Brierley, I, M E G Boursnell, M M Binns, B Bilımoria, V C Blok, T D K Brown, and S C Inglıs 1987 An efficient ribosomal frame-shiftıng signal in the polymerase-encoding region of the coronavirus IBV EMBO J 6 3779-3785

Brierley, I, P Digard, and S C Inglis 1989 Characterisation of an efficient coronavirus ribosomal frameshifting signal requirement for an RNA pseudoknot Cell 57 537-547

Fuerst, T R, E G Nıles, F W Studier, and B Moss 1986 Eukaryotıc transient-expression system based on recombinant vaccinıa virus that synthesises bacteriophage T7 RNA polymerase Proc Natl Acad Sc1 USA 83 8122-8127

Gorbalenya, A E, V M Blınov, and A P Donchenko 1986 Polıovirus-encoded protenase 3C a possible evolutionary link between cellular serıne and cysteıne protennase families FEBS lett 194:253-257

Gorbalenya, A E, E V Koonın, A P Donchenko, and V M Blınov 1989 Coronavirus genome prediction of putative functional domains in the non-structural polyprotein by comparative amino acid sequence analysıs Nucleic Acids Res 17 4847-4860

Liu, D X, D Cavanagh, P Green, and S C Inglis 1991 A polycıstronıc mRNA specified by the coronavirus infectious bronchitis virus Virology 184:531-544

Liu, D X, and S C Inglis 1992 Identification of two new polypeptıdes encoded by mRNA5 of the coronavirus infectious bronchitıs virus Virology 186:342-347

Liu, D X, Brierley, I , Tibbles, K W, and Brown, T D K (1994) A 100-kilodalton polypeptide encoded by open reading frame (ORF) $1 \mathrm{~b}$ of the coronavirus infectious bronchitis virus is processed by ORF la products $\mathrm{J}$ Virol $\mathbf{6 8}$, in press

Matthews, D A, W W Smith, R A Ferre, B Condon, G Budahazı, W Sisson, J E Villafranca, C A Janson, H E Mcelroy, C L Gribskov, and S Worland 1994 Structure of human rhinovirus 3C protease reveals a trypsin-lıke polypeptıde fold, RNA-binding site, and means for cleavıng precursor polyprotein Cell 77:761-771

Oberst, M D , T J Collan, M Gupta, C R Peura, J D Zydlewskı, P Sudarsanan, and T Glen Lawson 1993 The encephalomyocarditis virus $3 \mathrm{C}$ protease is rapidly degraded by an ATP-dependent proteolytic system in reticulocyte lysate Virology 193:28-40

Palmenberg, A C 1990 Proteolytic processing of picornaviral polyproteın Annu Rev Microbıol 44:603623

Smith, A R, M E G Boursnell, M M Binns, T D K Brown, and S C Inglis 1990 Identification of a new membrane-associated polypeptide specified by the coronavirus infectious bronchitis virus $\mathrm{J}$ gen Virol 71 3-11

Stern, D F and S I T Kennedy 1980a Coronavirus multiplication strategy I Identification and characterisation of virus specified RNA species to the genome $\mathrm{J}$ Virol 34:665-674

Stern, D F and S I T Kennedy 1980b Coronavirus multıplıcation strategy II Mapping the avian infectious bronchitis virus intracellular RNA species to the genome J Virol 36:440-449

Stern, D F and B M Sefton 1984 Coronavirus multiplication location of genes for virion proteins on the avian infectious bronchitis virus genome J Virol 50:22-29 